\title{
Feasibility and Interest of Continuous Diaphragmatic Fatigue Monitoring Using Wavelet Denoising in ICU and Anesthesia
}

\author{
Guy-Louis Morel $^{4}$, ${ }^{*}$ Philippe Mahul ${ }^{1}$, Marcelle Reche $^{3}$, Jean-Paul Viale ${ }^{2}$, Christian Auboyer ${ }^{1}$, \\ André Geyssant ${ }^{4}$, Frédéric Roche ${ }^{3}$, Jean-Claude Barthelemy ${ }^{3}$ and Vincent Pichot $^{3}$ \\ ${ }^{1}$ Intensive Care Unit, North Hospital, University Hospital, Saint-Etienne, PRES Lyon, France \\ ${ }^{2}$ Surgical Intensive Care Unit, Croix-Rousse Hospital, University Hospital, PRES Lyon, France \\ ${ }^{3}$ University North Hospital, Clinical and Exercise Physiology, and University Jean Monnet, EA4607, SNA-EPIS, PRES \\ Lyon, France \\ ${ }^{4}$ Exercise Physiology Laboratory, EA4338, and SNA-EPIS EA4607, University Jean Monnet, Saint-Etienne, PRES \\ Lyon, France
}

\begin{abstract}
Measures of diaphragmatic electromyography (Edi), and respiratory mechanics, have demonstrated early changes before clinical complications. However, automatic Edi data collection is not adequate today due mainly to severe artefacts as well as to loss of signal. We thus intended to develop a new device with embedded artificial intelligence to optimize automatic Edi recordings independantly of artefacts and of probe displacement.

We first chose the best mathematical tool to denoise Edi, using an established database, giving multiresolution wavelets as the best, resulting in the permanent availability of the $\mathrm{H} / \mathrm{L}$ spectral index, a recognized representative of diaphragmatic fatigue. Fatigue was simultaneously measured using the classical mechanical f/Vt index (Rapid Shallow Breathing Index, RSBI), as well as the transdiaphragmatic pressure.

We then performed a comparison of real-time $\mathrm{H} / \mathrm{L}$ and RSBI in a group of seven healthy volunteers, before and during midazolam sedation infusion $0.1 \mathrm{mg} \cdot \mathrm{kg}^{-1}$, with a parallel CPAP administration $\left(2.5,5.0\right.$, and $\left.10 \mathrm{~cm} \mathrm{H}_{2} \mathrm{O}\right)$ intended to compensate for airways resistance due to midazolam. Procedure was ended by delivering the antagonistic flumazenil 0.2 to $0.5 \mathrm{mg} \cdot \mathrm{kg}^{-1}$. Progressive fatigue due to midazolam, the relief due to CPAP, as well as the answer to the anatgonist flumazenil, were shown earlier by the $\mathrm{H} / \mathrm{L}$ index than by the RSBI change.

Our new H/L monitoring device may greatly improve clinical follow-up of anesthetized patients as well as help to determine the optimal period for ventilatory weaning in ICU (Clinical Trials NCT00133939).
\end{abstract}

Keywords: Diaphragmatic fatigue, electromyography, respiratory assistance, wavelets denoising, ventilatory weaning.

\section{INTRODUCTION}

In ICU, the concept of ventilation weaning is a common and difficult problem to solve $[1,2]$. The transition from full ventilation assistance, without any muscle solicitation, to spontaneous mobilization of respiratory muscles, is a difficult and dangerous step because the ability of the muscle to cope with ventilatory needs is not easy to establish [3] and early spontaneous ventilation may be unsafe $[4,5]$. Conversely, a prolongation of unneeded ventilatory assistance may be source of additional complications.

*Address correspondence to this author at the Exercise and Physiology Laboratory, CHU Nord, 42055 Saint-Etienne, France;

Tel: +33 477828 300; Fax: +33 477828 447;

E-mail: guy.morel@univ-st-etienne.fr
To better identify the time of recovery, attempts to evaluate diaphragmatic fatigue were already performed [6-9], through various mathematical methods $[10,11]$, aiming at improving extraction of diaphragmatic EMG (Edi) signals, without however convincing results [12].

To answer that problematic, we first used an established database analysis built from patients recorded in ICU to compare different mathematical methods of Edi denoising, Edi being a complex signal affected by many concurrent electrical signals $[13,14]$. Then, in another step, we added specific hardware and software to take into account the ventilatory movements which displace the diaphragmatic probe at each ventilatory cycle.

Secondly, the multiresolution wavelet analysis $[15,16]$ selected after that mathematical selection, was used to correlate with ventilatory parameters in a group of seven healthy 
subjects during anesthesia to evaluate our Edi monitoring apparatus. In that clinical setting, we monitored real-time diaphragmatic electromyogram (Edi), airway pressure (Paw), transdiaphragmatic pressure (Pdi) [17, 18], respiratory flow $(\dot{V})$, tidal volume $(\mathrm{Vt})$, breathing rate (f) and the so-called Rapid Shallow Breathing Index, f/Vt [19]. Edi measurement lead to several variables [20], particularly the ratio high over low frequencies $(\mathrm{H} / \mathrm{L})$ which was already described a pertinent representation of diaphragmatic fatigue, however without using real-time analysis, not available at that time [21]. The validation group used to assess the complete real-time monitoring hardware and software consisted in seven healthy subjects who were infused midazolam under ventilatory assistance [22].

\section{THE TECHNICAL STUDY.}

\subsection{Subjects and Data from the ICU}

The available ICU database included seven patients admitted for acute respiratory failure in the context of chronic obstructive pulmonary disease (COPD) [23].

Edi signal extraction was best performed using Multiresolution wavelets (MuRw) which correctly eliminated artefacts, particularly the ECG signal, and gave a favorable signal / noise (SNR) ratio, at no cost for the computational speed. The best pair of computational performances was given for $\mathrm{MuRw}$ with a SNR ratio $80.82 \pm 4.04 \mathrm{~dB}$ and a CPU time 0.22 second between signal acquisition and result availability. Lifting wavelets ( $\mathrm{LiFw}$ ) gave similar results for SNR but with more inconstancy in the signal quality (78.35 \pm 14.11 ; CPU time 0.168 second), and Morphological
Filter (MoFi) was about 5 times longer to compute (SNR 61.16 \pm 3.73 ; CPU time 1.06 second).

\subsection{Apparatus}

The nasal introducer (20F, $6.675 \mathrm{~mm}$ diameter) was equiped distally with an Edi probe $(8 \mathrm{~F})$ made of a silicon tube, 1200 millimeters length and 2,667 millimeters diameter, with 12 annular electrodes inserted on it each 10 millimeters from its distal end (Dräger Medical Electronics, Best, Netherlands), and with two piezoelectric pressure probes (MTC, Catheter F8 HD58, Full scale $400 \mathrm{~cm} \mathrm{H}_{2} \mathrm{O}$ ) one for gastric (Pga) and the other for oesophageal pressure (Pes).

Two external sensors are connected to a Flesh pneumotachograph to measure continuously the respiratory flow ( $\dot{V}$, Pressure sensor LCVR type (variable reluctance), 0-1000 $\mathrm{cmH}_{2} \mathrm{O}$, Celesco, Chatsworth, CA-USA), and the airway pressure (Paw, Pressure sensor SCX05DN, Sensortechnics$\mathrm{GmbH}$, Puchheim, Germany, full scale $350 \mathrm{cmH}_{2} \mathrm{O}$ ), in order to estimate the strength of respiratory muscles. An electronic card zero crossing detectors, in-house developed hardware and software, measuring breathing rate and inspiratory and expiratory time was specifically developed.

The hardware (Fig. 1) contains five processors dedicated to Edi, Pes, Pga, Flow, and Paw signal processing respectively. A real-time automatic check is carried out to permanently identify the pair of Edi electrodes giving the best diaphragmatic signal (ARM RISC AVR processor, Atmel, San Jose, CA), through two multiplexers (Analog Device, Norwood, MA) which control one for electrodes 1 to 11 and the others for electrodes 2 to 12 . The Edi bandwidth filters extend from $5 \mathrm{~Hz}$ to $1500 \mathrm{~Hz}$ and the use of a galvanic input

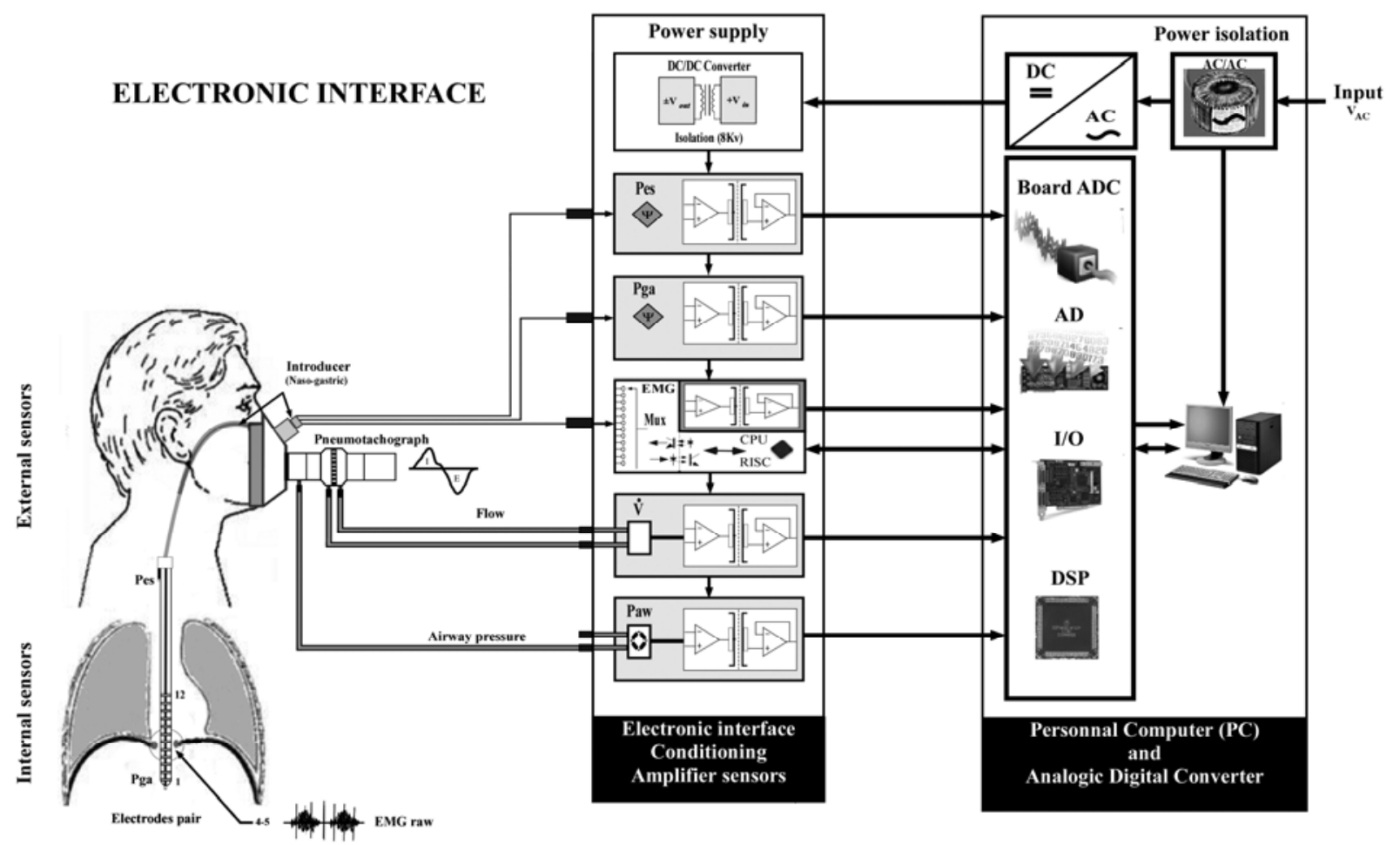

Fig. (1). Organization of internal sensors and of the electronic signal conditioning the four levels of the Internal sensors, Edi selector, Electronic interface, personal computer (ADC card). The data acquisition (ADC, DSP treatment) is performed through the Personal Computer (PC). 


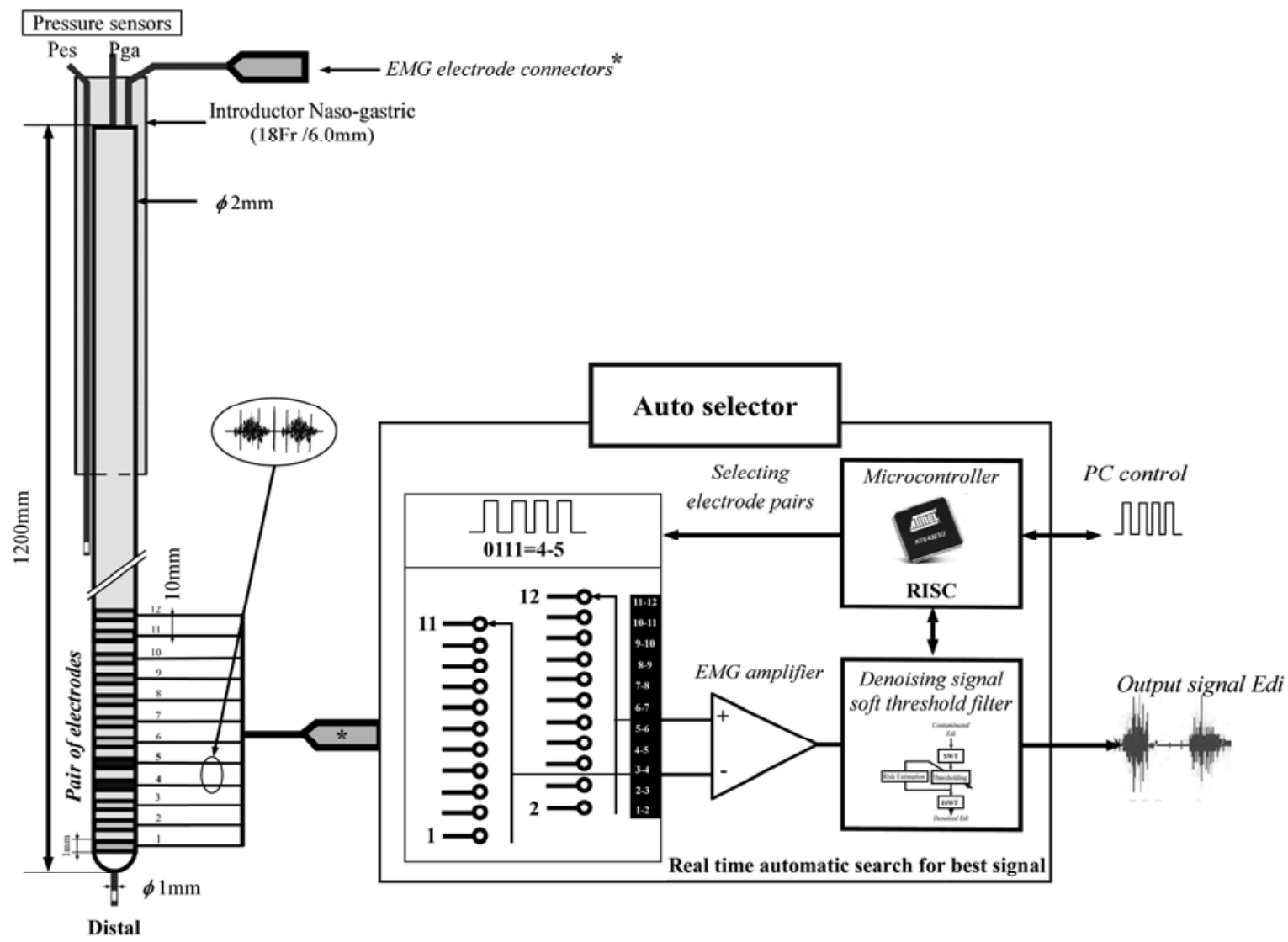

Fig. (2). Process of the treatment of internal and external signals, by an electronic interface selector Edi (RISC processor). The PC also drives the automatic diaphragmatic selector. The automatic selector allows to identify the best pair of electrodes. Initially, the pair 4-5 is located in front of diaphragmatic muscle. Then, the software compares all pairs. Each analysis is automatically sequentially proposed to the operator which can interfere with the automatic detection through a manual mode.

isolation amplifier (Analog Devices, Norwood, MA) is added for patient safety requirement (Fig. 2).

The A/D interface is a DAP 2400e/4, with 12 bits depth, and an overall sample rate of $312 \mathrm{KHz}$, which includes a CPU and a Digital Signal Processor (Microstar Laboratories, Bellevue, WA). The data acquisition processor combines analog data acquisition hardware with a 16 bits microprocessor, and a real-time multitasking operating system. All signals were acquired at a sampling frequency of $3 \mathrm{kHz}$ per channel.

Dedicated software was elaborated, using Matlab (version R2010b, MathWorks, Natick, MA).

\subsection{Mathematical Approach}

The Edi signal is first specifically detected using equation (1).

Signal (s) on noise $(n)$ ratio $\frac{s^{2}}{n^{2}}(v)=\frac{P_{E M G_{(v)}{ }^{2}}}{P_{\left.E M G_{(v)}+n o i s e\right)^{2}}}$

We evaluated three for Edi raw signal (Fig. 3 panel a) denoising, Multiresolution wavelet analysis (MuRw), Lifting scheme wavelet analysis (LiFw), and Morphological filter analysis $(\mathrm{MoFi})$.

\subsubsection{Multiresolution Wavelet Analysis (MuRw)}

The MuRw analysis belongs to the space $L^{2}(\mathbb{R})$ of functions of one real variable continuous and square integral. Analysis to the resolution $(j)$ of the function $(f)$ contents per share will be a linear operator $\left(a_{i}\right)$ on $(f)$ such that $a_{i} f \in V_{i}$ ( $V_{i}$ is a subspace $L^{2}, a_{i}$ is a projector). Multiresolution analysis is constructed using the subspace $V_{i}$ nested into each other; each transition from one to another is the result of a change of scale. The wavelet transform uses translations and dilations of a fixed function, the mother wavelet, to analyze the signal over the entire frequency range (dilation) and its duration (translation). The wavelet basis is generated by the equation 2 :

$\psi_{a, b}(t)=\frac{1}{\sqrt{a}} \psi\left(\frac{t-b}{a}\right)$

where $\mathrm{a}$ and $\mathrm{b}$ represents the dilatation and translation, witch $a, b \in(\mathbb{R})$, and $a>0, \psi_{a, b}(t)$ is the family of wavelet generated by translation and dilatation $\psi(t)$. The signal is then converted into a function of two variables as equation 3 : 

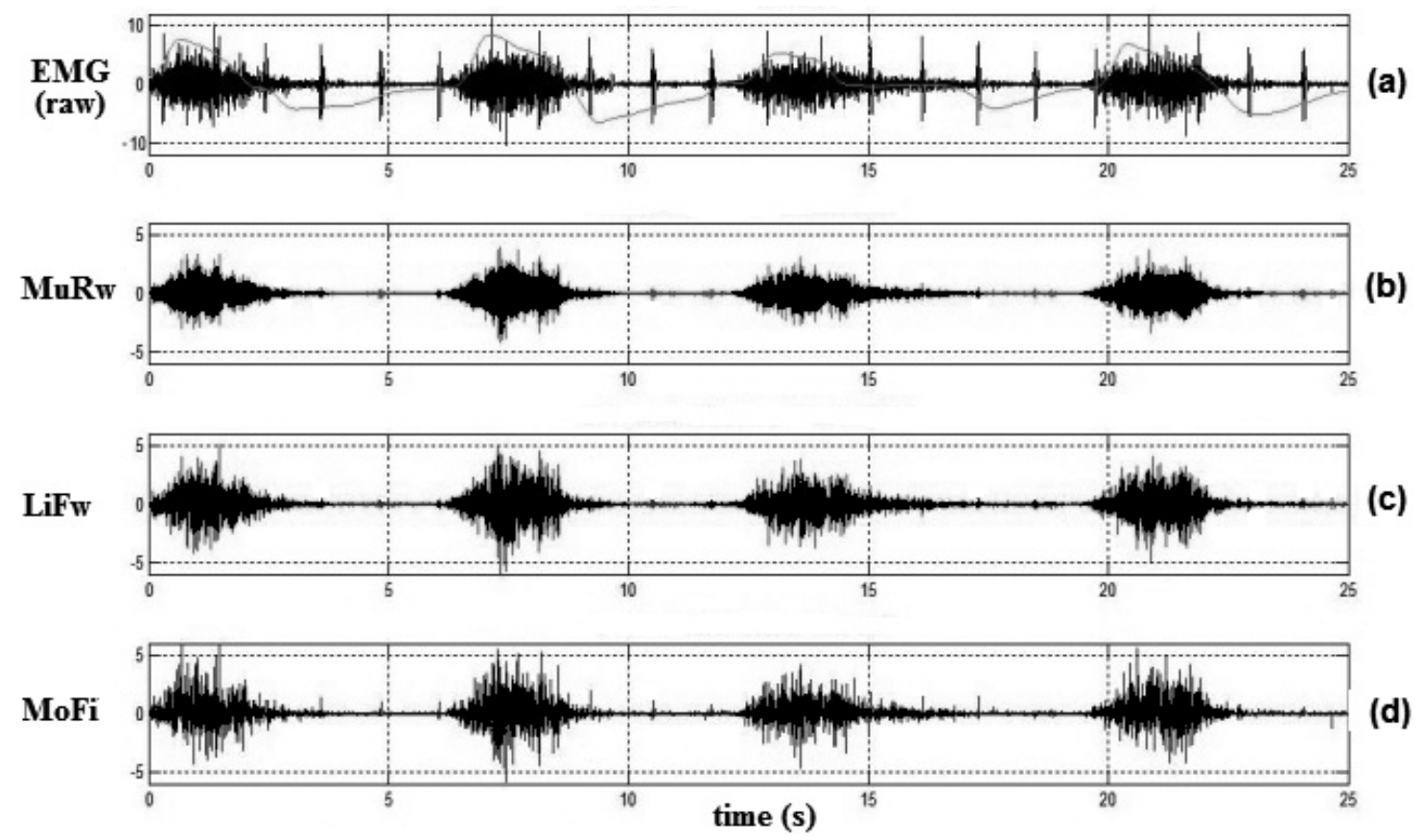

Fig. (3). Illustration of the results of the three denoising methods. (a) The EMG raw signal and the denoised signal using, (b) multiresolution wavelets analysis $(\mathrm{MuRw}),(\mathbf{c})$ new generation lifting $(\mathrm{LiFw})$ wavelets and (d) morphologic filter $(\mathrm{MoFi})$.

$W_{(a, b)}=\left\langle f, \psi_{a, b}\right\rangle=\frac{1}{\sqrt{|(a)|}} \int_{-\infty}^{\infty} x(t) \psi^{*}\left(\frac{t-b}{a}\right) d x$

For our transform, we use a signal that translates and dilates the wavelet discrete values according to coefficients $\boldsymbol{a}$ and $\boldsymbol{b}$, which are discretized: $a=a_{0}^{i}$ and $b=j \times b_{0} \times a_{0}^{i}$ $\left(a_{0}>1\right.$ and $b_{0}>0 \in \mathbb{R}$, and $\left.i, j \in \mathbb{R}\right)$. The wavelets are then defined by:

$\Psi_{i, j}(x)=\frac{1}{\sqrt{a_{0}^{i}}} \psi\left(\frac{1}{a_{0}^{i}} x-j b_{0}\right)$

The multiresolution wavelet analysis was introduced by Mallat [16]. He demonstrated that the wavelet coefficients defined by the relation $W_{(a, b)}=\left\langle f, \psi_{a, b}\right\rangle$ can be calculated from a pyramid transform implementation using digital filters. The principle of the pyramid transform is to decompose the signal to be analyzed using a pair of conjugate quadrature filters. One of these filters provides the wavelet coefficient $\mathrm{d}$, or detail, and the coefficients of the second provides the wavelet coefficients a, or approximation. The approximation is itself in turn decomposed by a second pair of filters, which together make up a pyramid of filters [24-26].

We use the multiresolution algorithm proposed by Mallat [16] to obtain approximation (a, equation 5), and details (d, equation 6), the original signal going through two filters, a high- and a low pass filter, using coefficients as follows. The wavelet analysis can thus be compared to an analysis in subband analysis.

$$
\begin{aligned}
& a_{n}(n)=\sum_{k} h(2 n-k) a_{m}-1(k) \\
& d_{n}(n)=\sum_{k} g(2 n-k) a_{m}-1(k)
\end{aligned}
$$

To denoise MuRw Edi signal, the process follows three recursive consecutive steps, 1) decomposition of the raw signal to choose the depth, 2) application of the thresholding of the coefficients of the decomposition using a thresholding method, 3) Reconstruction of the signal.

The coefficients of each filter output are sampled by a factor 2 in order to meet the Shannon sampling theorem (output coefficients, details). The second step consists in thresholding the details by soft thresholding, which penalizes the coefficients. Oppositely to the classical approach for denoising, the approximation sub-band is set to zero, as it represents the ECG signal, and only the details are kept for further reconstruction of the signal.

The soft thresholding is performed [27-30], using the standard $T h=\sigma \sqrt{\left(2 \log _{e} N\right)}$ equation, where $\mathrm{N}$ is the number of sampling points of the signal and noise, $\sigma$, an estimate based on the median absolute deviation of the details at level 1. The details $d$ coefficients are thresholded at each level of decomposition; the coefficients are set to zero. To improve the denoising, we chose to modify the threshold so that it takes into account the magnitude of detail. We take a threshold multi-scale SURE $T h_{j}$, $(j=$ level) calculated by minimizing the risk estimate of scale $\left(2_{j}\right)$ with the threshold $\left(T h_{j}\right)$. The threshold is calculated as $T h=\sigma \sqrt{\left(2 \log _{e}(N)-\log _{e}(\log (N))\right.}$ 
That thresholding method was used in order to avoid introducing discontinuity in the reconstructed signal (equation 7).

$$
\left.\left.a_{m-1}(k)=\sum_{k} h[2 n-k) a_{m}\right](k)+\sum_{k} g[2 n-k) d_{m}\right](k)
$$

The reconstruction filters the signal is given by equation 8 and the results are illustrated in Fig. (3) panel b.

$$
\left.\left.a_{m-1}(k)=\sum_{k} \tilde{h}[2 n-k) a_{m}\right](k)+\sum_{k} \tilde{g}[2 n-k) d_{m}\right](k)
$$

\subsubsection{Lifting scheme wavelet analysis (LiFw)}

Lifting scheme or $2^{\mathrm{d}}$ generation wavelet $(\mathrm{LiFw})$, is an improved wavelet analysis [31, 32], recently introduced and based on a Lazy Wavelet, which separates the signal in even and odd samples, while being free of Fourier approach. The analysis follows three consecutive steps.

Firstly, the original signal $(x)$ is decomposed (Lazy wavelet) as a polyphase matrix resulting in two bands $(x) \rightarrow\left(x_{\text {even }}, x_{\text {odd }}\right)$. The entries signal $x=\left(x_{k}\right)_{k \in \mathbb{R}}$ (with $x_{k}=\in \mathbb{R}$ ) is splited in two disjoint sub-groups. That spliting determines a sub-sampling of the original signal, the two resulting sub-groups being closely correlated with $x_{\text {even }}=\left(x_{k}\right)_{k \in \mathbb{R}}$ and $x_{\text {odd }}=\left(x_{2 k+1}\right)_{k \in \mathbb{R}}$.

Secondly, a predict factor $\mathrm{P}$ (dual lifting) is ap$\operatorname{plied}\left(x_{e}, x_{0}\right) \rightarrow\left(x_{e}, d\right)$, consisting in a high-pass filter and a sub-sampling of the signal $(x)$. We thus record the difference, or details, as: $d=x_{\text {even }}-P\left(x_{\text {odd }}\right)$, and we thus have the even data as $x_{\text {even }}=P\left(x_{\text {odd }}\right)+d$.

Thirdly, to correct the obtained low frequency signal, we update (U, primal lifting). The $\mathrm{U}$ operator allow to keep the main characteristics contained in the original signal using $s=x_{\text {even }}+U(d)$. That step, denominated lifting step, $\left(x_{e}, d\right) \rightarrow(s, d)$, is invertible $x_{\text {even }}=s-U(d)$, as was $\mathrm{s}$ and $\mathrm{d}\left(x_{e}, d\right) \rightarrow(s, d)$.

Several advantages favor Lifting Wavelet against Multiresolution wavelet, as the possibility to have real-time analysis and the choice to change the mother wavelet during the course of the analysis. Whatever the wavelet used, the method consists in factorizing polyphase matrix in elementary steps. The number of steps may vary considerably according of the selected wavelet. The polyphase matrix calculation of an $h(z)$ filter is given through the following equation 9 and equation 10 :

$h(z)=h_{e}\left(z^{2}\right)+z^{-1} h_{0}\left(z^{2}\right)$

where $h_{e}$ and $h_{0}$ correspond to the components of the polyphase matrix.

$h e(z)=\sum_{k} h_{2} z^{-k}$ and $h_{0}(z)=\sum_{k} h_{2 k+1} z^{-k}$
Similar relationships as those between equation (9) and (10) are used to take the $g(z)$ high-pass filter into account. The use of synthesis filters $h(z)$ and $g(z)$ allows to construct the polyphase matrix (equation 11).

$$
P(z)=\left(\begin{array}{ll}
h_{e} & g_{e} \\
h_{0} & g_{0}
\end{array}\right)
$$

With the help of the perfect reconstruction condition $\tilde{P}\left(z^{-1}\right)^{t} P(z)=1$, it becomes possible to deduct the polyphase matrix of analysis $\tilde{P}(z)$. The algorithm proposed by Daubechies and Sweldens [33] proceeds, for each $P(z)$ and $\tilde{P}(z)$ matrix, to the extraction of the dual lifting step $t_{i}(z)$ and of the primary lifting $s_{i}(z)$. The $t_{i}(z)$ and $s_{i}(z)$ are functions of Laurent. The predictor, $\mathrm{P}$, is assessed from an odd sample giving an even sample, and conversely (equation 12), all along the signal.

$P_{z}=\left(\begin{array}{ll}\alpha_{1} & 0 \\ 0 & \alpha_{2}\end{array}\right) \prod_{i=1}^{m}\left(\begin{array}{ll}1 & s_{i}(z) \\ 0 & 1\end{array}\right)\left(\begin{array}{ll}1 & 0 \\ t_{i}(z) & 1\end{array}\right)$

where $\alpha_{1}$ and $\alpha_{2}$ are constants $(\neq 0)$.

To rebuild the signal, we just need to perform the reverse of the Lifting Scheme transform. This consists in reversing the order of operations and the sign of operators. In our application, we selected orthogonal wavelets from Daubechies to apply the Lifting Scheme denoising method Edi signal. The results are illustrated in Fig. (3) panel c.

\subsubsection{Morphological Filter Analysis (MoFi).}

The morphological filter (MoFi) method is based on the theory of non-linear processing of information $[34,35]$. The identity with a shape for opening for closing morphological fundamental structure is that of a full lattice. It is based on reference shape giving a signal analyzed as a binary yes/no operators (equations 13,14, 15, 16). Usually used in image analysis, the method was adjusted to filter Edi signal, keeping an analysis with increasing size of the reference shapes. These results are illustrated in Fig. (3), panel d for the MoFi method.

$$
\begin{aligned}
& E_{b i n}(X)=\{x: B(x) \subseteq X\} \\
& D_{B i n}(X)=\{x: B(x) \cap X \cap \varnothing\} \\
& O_{b i n}(X)=D_{B i n}\left(E_{B i n}(X)\right) \\
& C_{B i n}(X)=E_{B i n}\left(D_{B i n}(X)\right)
\end{aligned}
$$

with: $\mathrm{E}=$ erosion, $\mathrm{D}=$ dilatation, $\mathrm{O}=$ opening, $\mathrm{C}=$ closing, $\mathrm{X}=$ signal to study, and Bin=binary

Any increasing transformation (equation 17) and idempotente (equations 18) on a lattice defines a morphological filter $[34,36]$. Idempotence means that an operation determines the same effect whether applied once or several times). 


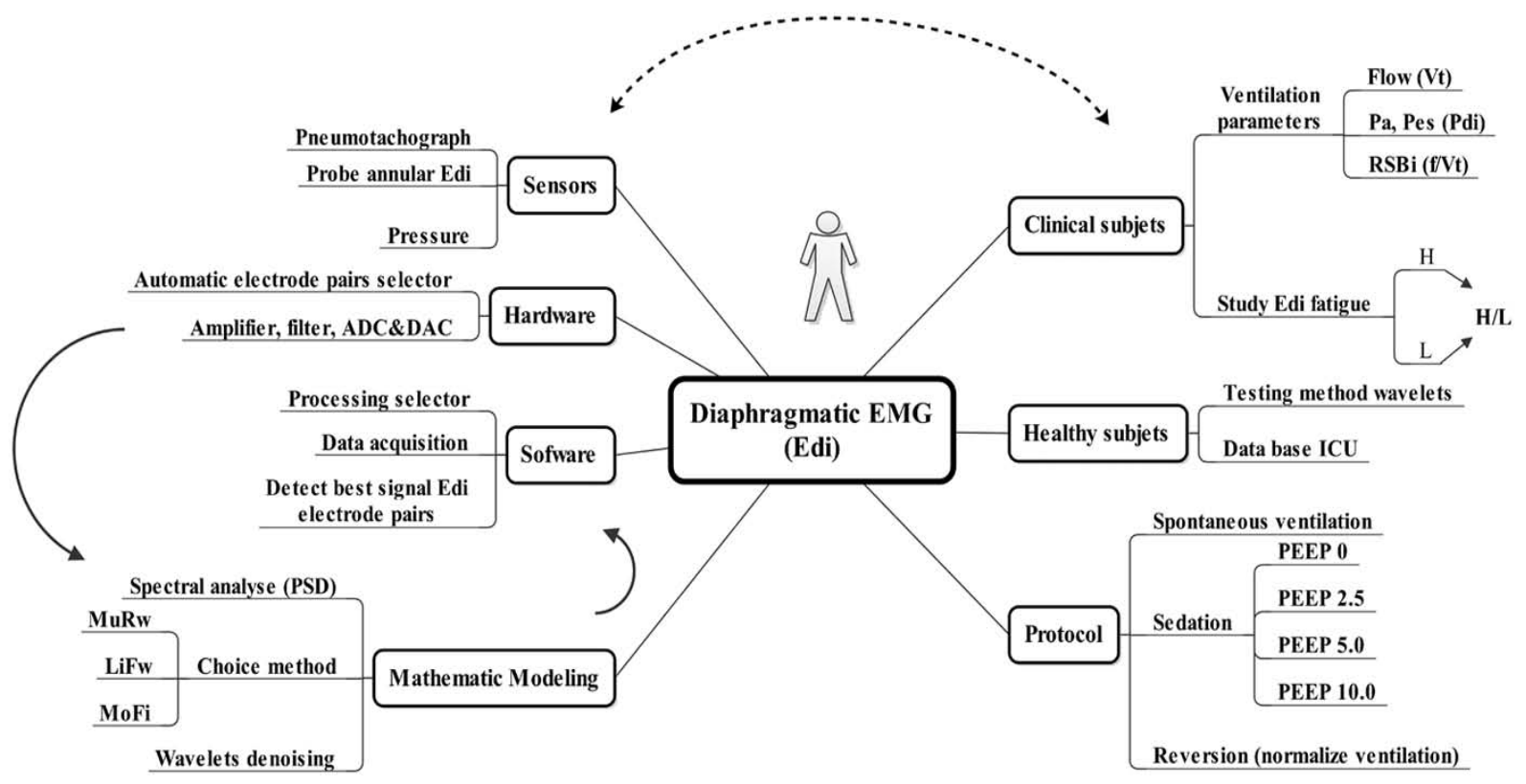

Fig. (4). Heuristic representation of the Diaphragmatic EMG (Edi) data treatment. On the left side are located the acquisition module and the mathematical evaluation while the clinical data are located on the right side.

$(x \leq y) \Rightarrow \Phi_{(x)} \leq \Phi_{(y)}$

$\Phi_{(x)}\left(\Phi_{(x)}\right)=\Phi_{(x)}$

with $\Phi: E \rightarrow E$.Morphological erosion and dilatation filters.

Two other operators are defined for opening and closing the procedure. The Opening is defined as: opening ${ }_{s}(X)=$ dilatation $_{s}\left(\operatorname{erosion}_{s}(X)\right)$, and the closing as : closing ${ }_{s}(X)=$ erosion $_{s}$ (dilatation ${ }_{s}(X)$ ) where $s$ is a structuring factor. These two operations are dual by complementation, with $\mathrm{s}^{*}$ as a symmetric of s: opening ${ }_{s} *(X)=\left[\operatorname{closing}_{s}\left(X^{c}\right)\right]^{c}$ et closing $_{s^{*}}(X)=\left[\text { opening }_{s}\left(X^{c}\right)\right]^{c}$. In our analysis, the noise reduction of opening and closing was compared to those of the two preceding methods used as:

Edi $=$ Edi $_{\text {raw }}$ - closing (opening $\left.\left(\operatorname{Edi}_{\text {raw }}, \alpha\right)\right)$

where $\alpha$ : parameters of the filter.

\subsubsection{Choice of the Mathematical Method}

Amongst the three denoising methods evaluated, MuRw appears as the most performing method due to the combination of the resulting signal/noise ratio and speed of computing, without compromise on the stability of artifact rejection and the associated real-time visual display. The quality of that mathematical approach allows a precise measurement of Edi frequency parameters, and particularly of the H/L ratio.

The power spectral density (PSD) [37] is calculated from the denoised signal, allowing quantification of diaphragmatic fatigue. High, 130-250 Hz, and low, 30-50 Hz, frequencies are calculated so as to establish the $\mathrm{H} / \mathrm{L}$ ratio, from equation 19.

$$
\frac{H}{L}=\frac{\int_{130}^{250} P S D(f) d f}{\int_{30}^{50} P S D(f) d f}
$$

The apparatus, the mathematical modeling, and the following clinical evaluation are all part of an heuristic model dedicated to Diaphragmatic activity monitoring (Fig. 4).

\section{THE CLINICAL STUDY}

\subsection{Methods}

\subsubsection{The Real-time Study Subjects}

A group of seven healthy male volunteers subjects free of any clinical abnormalities aged $34 \pm 16$ years; $67 \pm 15 \mathrm{~kg}$; $1.76 \pm 0.8 \mathrm{~m}$, was included after they signed an informed consent. The study (Clinical Trials ID NCT00133939) was approved by the University Hospital and the IRB-IEC (CCP Sud Est 1, Rhône-Alpes France) as well as by the French Health Authority Product Safety Agency (AFSSAPS).

Each subject had a 12-hour stay in the hospital, the first 2 hours for the experiment, and the last 10 hours for medical monitoring. The subject received first a venous catheter for drug delivery. Then the probes were placed, after local mucosae nasal anesthesia through Lidocaine spray, using the same introducer, in gastric position for electrodiaphragmatic monitoring, and in the oesophagus and in the stomach for transdiaphragmatic pressure. The facial pneumotachgraph was then placed to monitor ventilatory flow and airway pressure. The first measures performed in ambient air serve as references values.

Midazolam infusion was induced by an anaesthesiologist who monitored the subjects all along the protocol. The protocol (Fig. 5) was performed in a labelled pharmacological research clinical setting. Physiological measures lasted 40 minutes. A first measurement was performed before any drug administration, during the first 10 minutes. Midazolam induces an increase in airway resistance, due to central ventilatory sedation and peripheral decrease of muscular activity. 
Table 1. Average Values of the Parameters Mechanicals and Electric Parameters Ventilatoire During the Three Periods (Basal, Sedation, Reversion), as mean (SD). An the Group of Seven Healthy Subjects

\begin{tabular}{|c|c|c|c|c|c|c|}
\hline \multirow{2}{*}{ Parameters } & Control & \multicolumn{4}{|c|}{ Infusion } & \multirow{2}{*}{$\begin{array}{c}\text { Waking } \\
\text { Reversion } \\
\text { (Flumazenil) }\end{array}$} \\
\hline & Basal (SD) & Peep 0 & Peep 2.5 & Peep 5.0 & Peep 10 & \\
\hline $\begin{array}{l}\text { Vt } \\
\text { (1) }\end{array}$ & $\begin{array}{c}0.273 \\
(0.018)\end{array}$ & $\begin{array}{c}0.166 \\
(0.012)\end{array}$ & $\begin{array}{c}0.213 \\
(0.028)\end{array}$ & $\begin{array}{c}0.190 \\
(0.020)\end{array}$ & $\begin{array}{c}0.250 \\
(0.027)\end{array}$ & $\begin{array}{c}0.193 \\
(0.007)\end{array}$ \\
\hline $\begin{array}{c}\mathbf{f} / \mathbf{V t} \\
\left(\mathrm{B} \cdot 1 \cdot \mathrm{mn}^{-1}\right)\end{array}$ & $\begin{array}{l}51.5 \\
(5.0)\end{array}$ & $\begin{array}{l}140.3 \\
(5.5)\end{array}$ & $\begin{array}{l}146.3 \\
(8.7)\end{array}$ & $\begin{array}{c}138.2 \\
(6.7)\end{array}$ & $\begin{array}{l}122.8 \\
(7.4) \\
\end{array}$ & $\begin{array}{l}92.8 \\
(3.6)\end{array}$ \\
\hline $\begin{array}{c}\text { Pga } \\
\left(\mathrm{cmH}_{2} \mathrm{O}\right)\end{array}$ & $\begin{array}{c}3.3 \\
(1.9)\end{array}$ & $\begin{array}{c}2.3 \\
(1.3)\end{array}$ & $\begin{array}{c}2.6 \\
(1.4)\end{array}$ & $\begin{array}{c}2.4 \\
(1.2)\end{array}$ & $\begin{array}{c}2.4 \\
(1.1)\end{array}$ & $\begin{array}{c}3.6 \\
(1.9)\end{array}$ \\
\hline Pga/Pes & $\begin{array}{c}0.8 \\
(0.7)\end{array}$ & $\begin{array}{c}0.11 \\
(0.04)\end{array}$ & $\begin{array}{l}0.17 \\
(0.1)\end{array}$ & $\begin{array}{l}0.24 \\
(0.1)\end{array}$ & $\begin{array}{l}0.33 \\
(0.2)\end{array}$ & $\begin{array}{l}0.71 \\
(0.5)\end{array}$ \\
\hline $\begin{array}{c}\text { Pdi } \\
\left(\mathrm{cmH}_{2} \mathrm{O}\right)\end{array}$ & $\begin{array}{c}8.21 \\
(3.20)\end{array}$ & $\begin{array}{c}23.0 \\
(1.00)\end{array}$ & $\begin{array}{l}18.69 \\
(1.27)\end{array}$ & $\begin{array}{l}12.31 \\
(4.88)\end{array}$ & $\begin{array}{l}10.19 \\
(4.82)\end{array}$ & $\begin{array}{c}9.01 \\
(1.50)\end{array}$ \\
\hline $\mathrm{H} / \mathrm{L}$ & $\begin{array}{c}0.933 \\
(0.005)\end{array}$ & $\begin{array}{c}0.710 \\
(0.011)\end{array}$ & $\begin{array}{c}0.691 \\
(0.086)\end{array}$ & $\begin{array}{c}0.724 \\
(0.004)\end{array}$ & $\begin{array}{c}0.809 \\
(0.007)\end{array}$ & $\begin{array}{c}0.877 \\
(0.005)\end{array}$ \\
\hline $\begin{array}{l}\text { Edi } \\
\text { (v) }\end{array}$ & $\begin{array}{c}0.109 \\
(0.057)\end{array}$ & $\begin{array}{c}0.268 \\
(0.093)\end{array}$ & $\begin{array}{c}0.258 \\
(0.148)\end{array}$ & $\begin{array}{c}0.218 \\
(0.135)\end{array}$ & $\begin{array}{c}0.154 \\
(0.098)\end{array}$ & $\begin{array}{c}0.106 \\
(0.045)\end{array}$ \\
\hline $\begin{array}{c}\text { Pdi/Edi } \\
\left(\mathrm{cmH}_{2} \mathrm{O}^{-\mathrm{V}}\right)\end{array}$ & $\begin{array}{c}98.9 \\
(66.7)\end{array}$ & $\begin{array}{l}111.8 \\
(86.8)\end{array}$ & $\begin{array}{c}135.8 \\
(169.7)\end{array}$ & $\begin{array}{l}89.6 \\
(67)\end{array}$ & $\begin{array}{c}105.1 \\
(77)\end{array}$ & $\begin{array}{c}110.7 \\
(74)\end{array}$ \\
\hline
\end{tabular}

This was progressively counteracted by increasing levels of continuous positive airway pressure (CPAP) set at successive positive end-expiratory pressure (PEEP) levels of 0.0 , 2.5, 5.0, and $10.0 \mathrm{~cm} \mathrm{H}_{2} \mathrm{O}$, each CPAP level being applied for five minutes. The last measurement was performed during the first 10 minutes following flumazenil administration. Recovery under monitoring lasted 10 hours, i.e. four half-life of midazolam.

\subsubsection{Measurement Procedure}

The sensors were initially set to zero against the atmosphere pressure. Ventilatory flow was measured through an external pneumotachograph. The ventilatory flow ( $\dot{V})$ was used as a time reference for synchronization of other signals. Calculated ventilatory parameters were i) tidal volume $(\mathrm{Vt})$, ii) ventilatory frequency (f) and iii) their ratio (f/Vt) also known as Rapid Shallow Breathing index (RSBI) [38], with a RSBI value below 105 being considered as normal, iv) inspiratory duration (Ti). The ratio f/Vt (RSBI) representing the strength of inspiratory activity is a recognized predictive indicator of weaning.

Oesophageal (Pes) and gastric (Pga) pressure, respectively measured above and below the diaphragmatic muscle allowed the transdiaphragmatic (Pdi) pressure to be calculated as Pga-Pes.
Diaphragmatic fatigue was measured through measurement of Pdi, RSBI, and Edi variables during the inspiration phase.

\subsubsection{Statistical Analysis}

Methods of diaphragmatic electrical analysis were compared for their signal/noise ratio and computing time using paired t-test. An analysis of variance (ANOVA) for repeated measurements was performed to compare the variations of the clinical parameters during the consecutive sedation periods, and a Fisher's test was applied when required. We compared two types of parameters, the mechanical (Vt, RSBI, Pdi), and the diaphragmatic electrical (Edi, H/L) parameters. Inspiration duration, $\mathrm{Ti}$, was also measured. Comparisons were significant at the $\mathrm{p} 0.05$ level.

\subsection{Results for the Clinical Validation Study}

The time duration of probes installation was about 15 minutes.

Following midazolam infusion the diaphragmatic muscle turns an intense low frequency, activity with an $\mathrm{H} / \mathrm{L}$ ratio which decreases sharply. The muscle activity fights against an increased airway resistance. Accordingly, Vt decreases and thus the f/Vt (RSBI) increases dramatically. Interestingly, there is thus a contrast between the increase in the 
filtered electrical diaphragmatic signal and the decrease in the $\mathrm{H} / \mathrm{L}$ ratio of the same muscle. The Pes is suddenly decreased from -4.9 to $-20.7 \mathrm{cmH}_{2} \mathrm{O}$, due to airway resistance increase, which indicates that, at that time, the diaphragmatic muscle is highly solicited and is still able to create a strong depression (Table 1). The Pdi evolution is exactly in mirror of Pes evolution (Fig. 6). At the same time, Vt decreases significantly, giving an increased f/Vt (Table $\mathbf{1}$ ).
In response to increasing CPAP compensation for the airway resistance induced by midazolam, the $\mathrm{H} / \mathrm{L}$ ratio is progressively corrected, and reach a significant level of correction for a $10 \mathrm{cmH}_{2} \mathrm{O}$ CPAP value (Fig. 6, Table 1, 2). Edi is progressively corrected as well. In response to that increase in CPAP compensation, Pdi returns progressively to basal value (Table 2) with a significant chenge for 10 $\mathrm{cmH}_{2} \mathrm{O}$ CPAP value. AT the same time, f/Vt (RSBI) presents a progressive correction decrease which becomes also

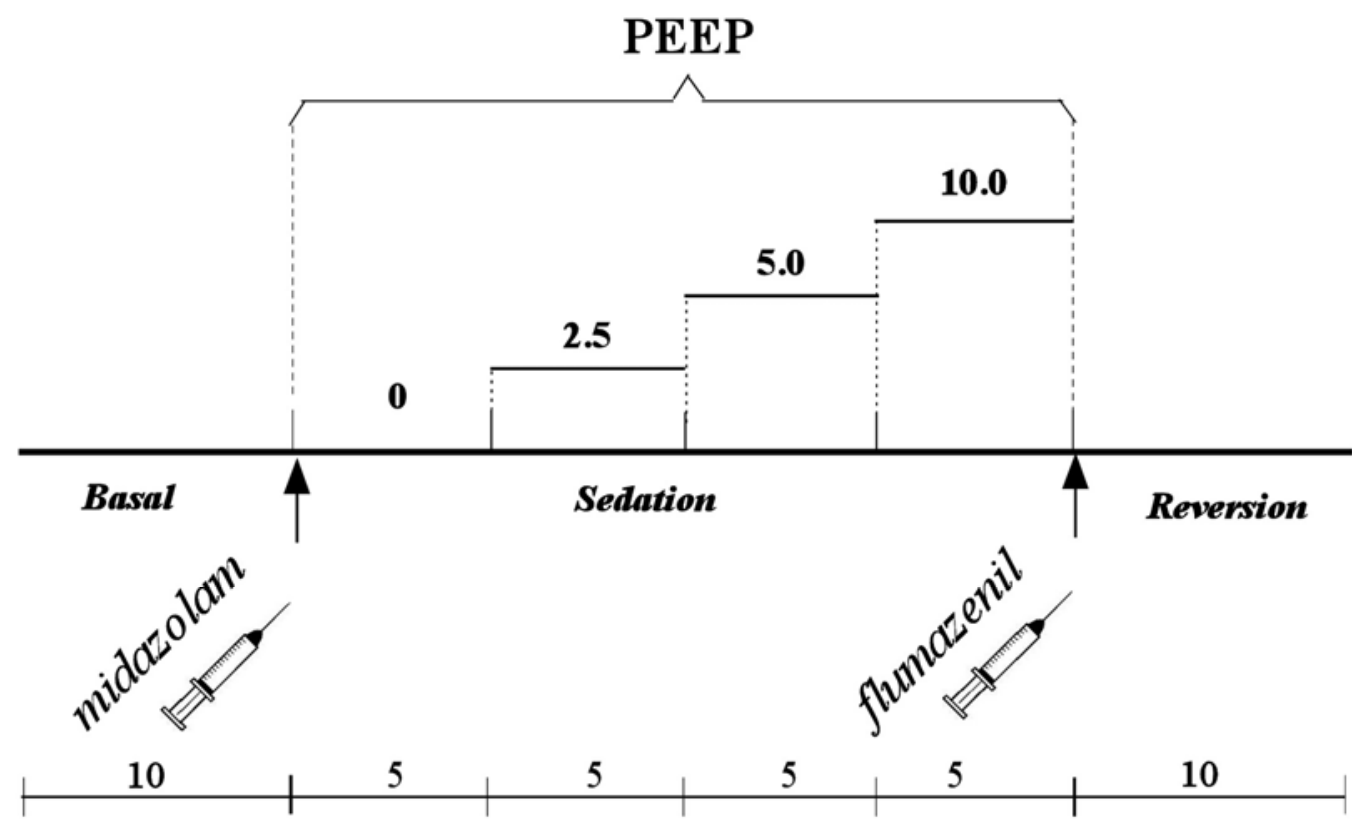

Time (mn)

Fig. (5). Midazolam infusion protocol. The Basal phase was the phase of pre-midazolam infusion data assessment. The Sedation phase was the period under midazolam, which included increasing CPAP stages. The Recovery period was induced by flumazenil.

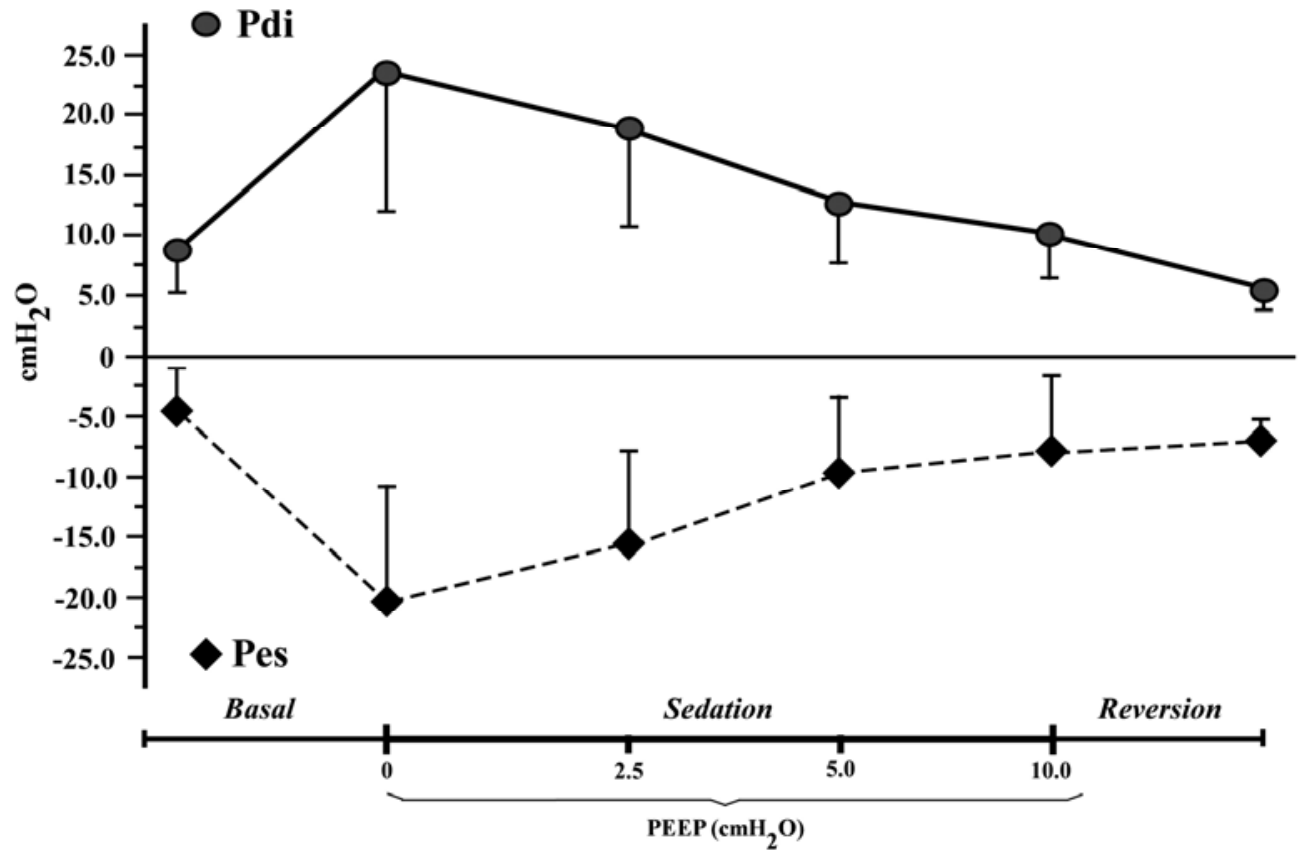

Fig. (6). Pressure Pes and Pdi (Pdi=Pga-Pes), evolution in response to Midazolam administration with various increasing PEEP. Of note the severe decrease in Pes under Midazolam without PEEP. The increase in PEEP corrects progressively for Pes. Pdi, abruptly elevated, normalizes progressively with increasing PEEP administration. 
Table 2. Represents the Variations of Parameters at Each Stage of the Study; Vt (Tidal Volume); Vt/Ti (Tidal Volume/Inspiratory Duration; Pdi (Transdiaphragmatic Pressure); f/Vt (Respiratory Frequency / Tidal/Volume); H/L (High / Low Frequency); Edi (Electromyogram Diaphragmatic Voltage). ${ }^{*}: \mathbf{p}<0.05 ; * *: \mathbf{p}<0.01 ; * * *: \mathbf{p}<0.001$.

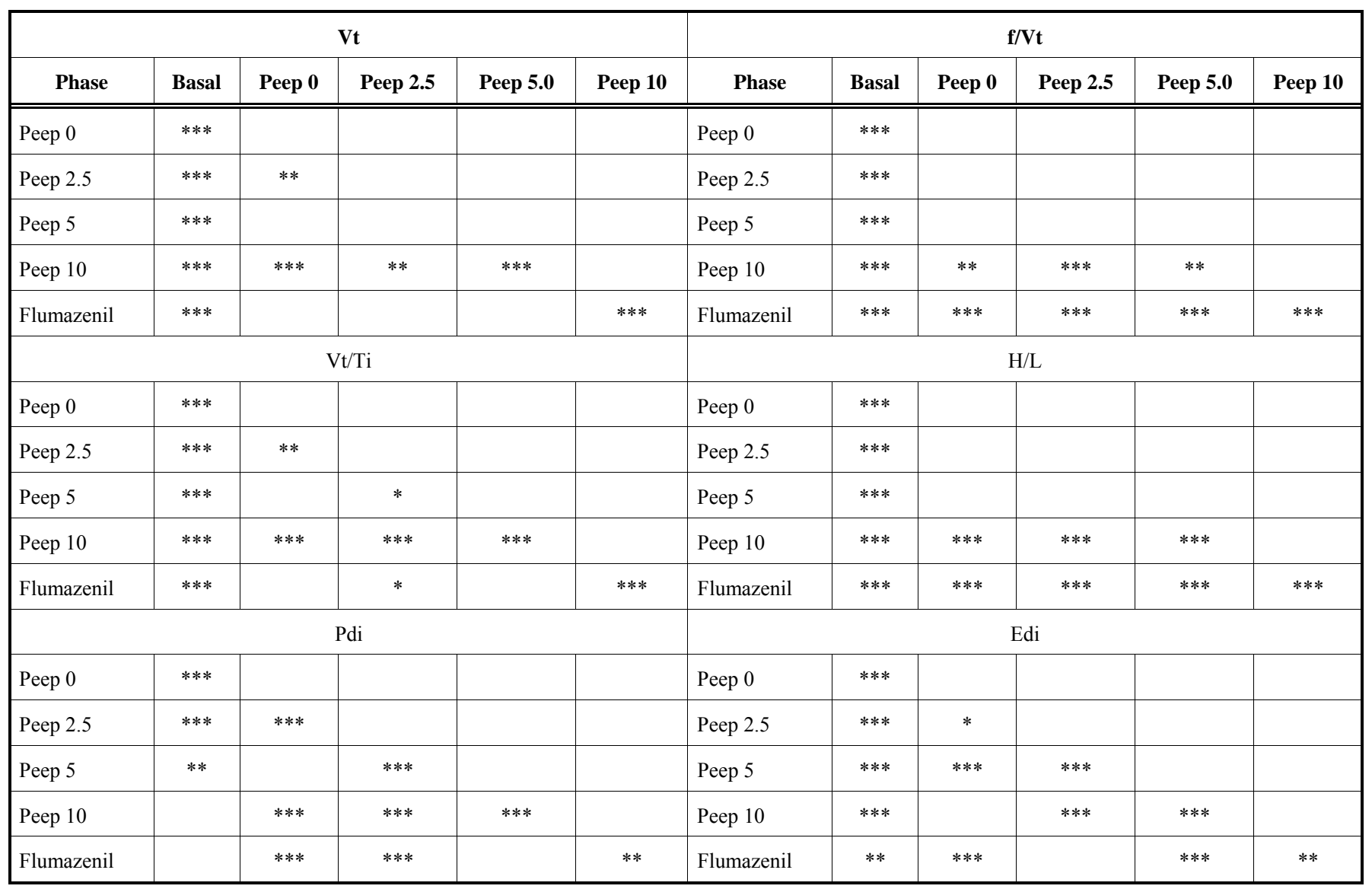

significant for the same $10 \mathrm{cmH}_{2} \mathrm{O} \mathrm{CPAP}$ value.

Due to a short post-flumazenil monitoring period, values did not return to their basal value during the recorded recovery period. This is true for $\mathrm{H} / \mathrm{L}$, as well as for $\mathrm{f} / \mathrm{Vt}$ (RSBI) [19].

The signals of muscular diaphragmatic fatigue occurred at different times of the procedure as, during sedation but before PEEP intervention, as $\mathrm{H} / \mathrm{L}$ change occurred about one minute before those of $\mathrm{f} / \mathrm{Vt}$ (RSBI). Similarly, the H/L 50\% decrease was reached approximately three minutes before the achievement of the admitted significant $\mathrm{f} / \mathrm{Vt}$ (RSBI) threshold, $105 \mathrm{ml}^{-1} . \mathrm{s}^{-1}$. During waking, $\mathrm{H} / \mathrm{L}$ was normalized at $80 \%$ of its reference value in less than two minutes while $\mathrm{f} / \mathrm{Vt}$ (RSBI) was normalized later, after more than one minutes, as already shown (Fig. 7).

\section{DISCUSSION}

The improvement brought by our monitoring system over previous diagnosis tools, is the benefits of a performing realtime monitoring due to implementation in one simple device of both well selected mathematical method added to a realtime automatic selection of the best raw Edi signal, allowing an easy clinical use [39, 40].

The final choice of MuRw [24, 41] comes from its constant ability to present a low signal/noise ratio, contrary to
LiFw [42-44], as well as to its ability to be used in a simple microchip controller. This low dispersion of MuRw SNR comes probably from the fact that it works on reals while LiFw uses integers giving a higher reproducibility of details than LiFw. The constant ability of MuRw to control for noise is brought at the price of a slightly slower process than LiFw, although not significantly different [36], while MoFi determines a CPU time five times longer.

A prerequisite to a good Edi measurement was a good initial position of the diaphragmatic probe, which was guided by the algorithm selecting automatically and constantly the best Edi electrodes pairs. All the subjects kept the probe in position giving good measurements all along the procedure.

Our apparatus allowed us to confirm that, in healthy subjects, the $\mathrm{H} / \mathrm{L}$ ratio of the diaphragmatic muscle activity, given the clinically established threshold of 0.80 [4], is the most significant variable to warn the anesthesiologist about diaphragmatic fatigue during the midazolam sedation. Furthermore, the warning comes minutes in advance on the $\mathrm{f} / \mathrm{Vt}$ values alteration. Through the $\mathrm{H} / \mathrm{L}$ diaphragmatic ratio, we thus made possible the real-time recognition of the first phase of respiratory distress, which is considered as highly reversible. Diagnosed later, the ventilatory fatigue, less reversible, would eventually need emergency ventilatory assistance $[4,5,9]$. This makes of real-time Edi frequential 


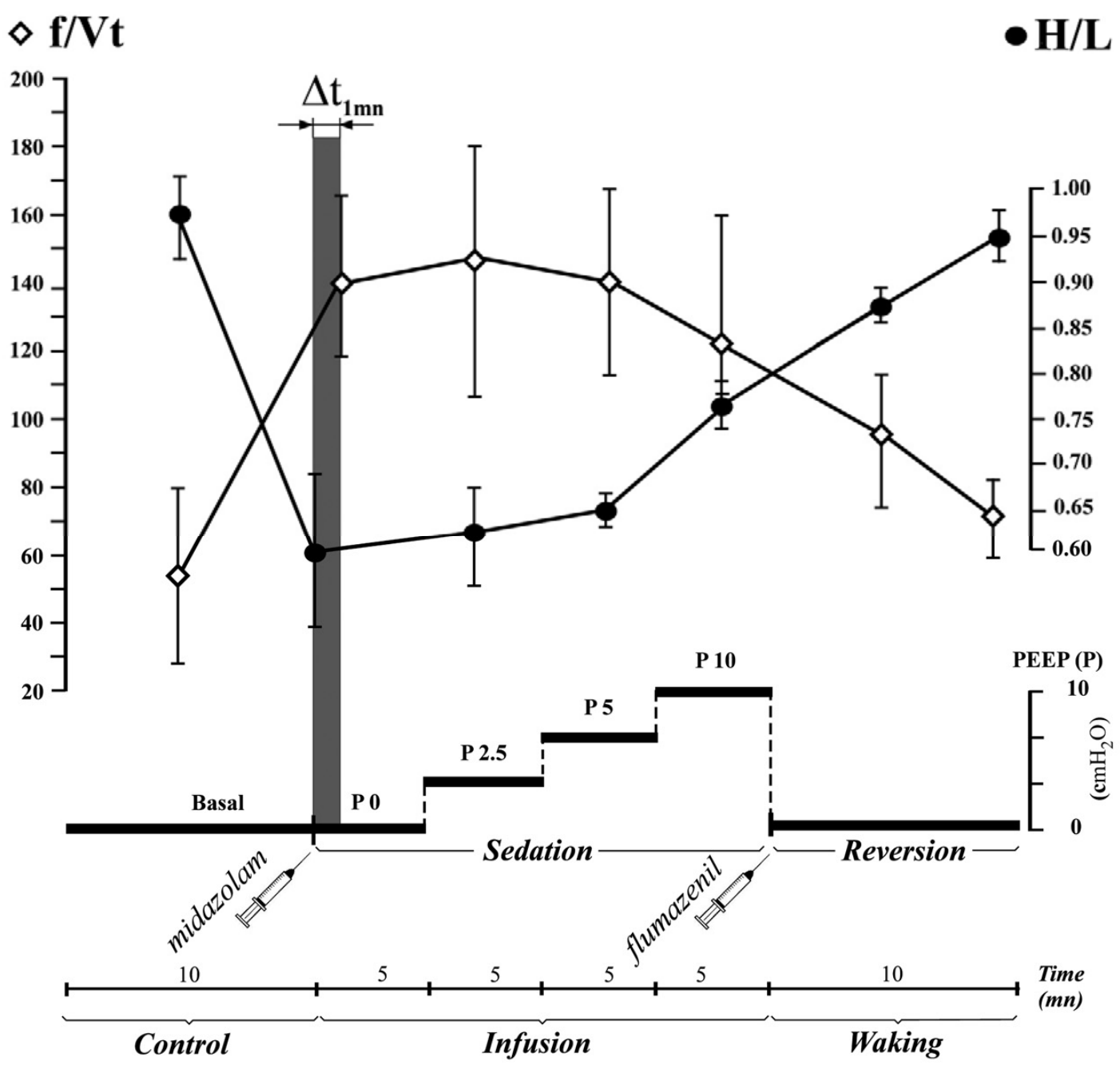

Fig. (7). Results of f/Vt (mechanical parameters) and $\mathrm{H} / \mathrm{L}$ (electrical parameters) measurements during the three phases of the protocol. Vertical bars are SD. It is clearly shown that midazolam infusion determines, in a shorter time than the $\mathrm{f} / \mathrm{Vt}$ increase, a sharp H/L decrease almost compensated by the $10 \mathrm{~cm} \mathrm{H} 20$ PEEP.

analysis a potential tool that may help to improve the therapeutic strategies in anesthesia and reanimation.

Our works confirm the previous observation of an initial decrease of $\mathrm{H} / \mathrm{L}$ ratio before the occurrence of an increase in ventilatory frequency, changes which however were not measured in real-time $[6,7,45]$. Our data confirm these works and adds real time $\mathrm{H} / \mathrm{L}$ parameter, while keeping available real time RSBI (f/Vt) measurement, an already recognized parameter [19]. Another analysis of Edi showed also that adding increasing mechanical inspiratory assistance in intubated patients corrected progressively the $\mathrm{H} / \mathrm{L}$ parameter $[4,5]$, underlining also the interest in real time $\mathrm{H} / \mathrm{L}$ assessment to assess the results of an intervention, while these works did not performed real-time measurements. The interest in real-time monitoring is further reinforced by the steep decrease in $\mathrm{H} / \mathrm{L}$ from 0.80 to 0.45 observed a few minutes after midazolam infusion, well before the appearance of clinical signs of distress.

Interestingly, we observed that the diaphragmatic H/L activity decrease preceded the variations of the ventilatory parameter f/Vt (RSBI) increase, which is known to represent the ventilatory central control response, both being signifi- cantly altered by midazolam infusion. $\mathrm{H} / \mathrm{L}$ decrease may be an earlier marker of central ventilatory command. The other ventilatory parameters as $\mathrm{Vt}$ and ventilatory pressure are known for their instability, due to mechanical artefacts as well as the probes errors due to breathing water vapor. Also, the significance of $\mathrm{f} / \mathrm{Vt}$ (RSBI) may be altered in some conditions, as when ventilatory parameters may be imposed during prolonged periods of time, making the diaphragmatic electrical activity measurement the only remaining variable available to assess ventilatory fatigue [46-48].

CPAP was evaluated in that context to quantify the benefit brought by reopening the induced midazolam infusion airways constriction. The benefits are mediated through an increase in functional residual capacity, and a decrease in residual volume which increases alveolar recruitment, leading to a diaphragmatic relief. We did not use a CPAP above ten centimeters $\mathrm{H}_{2} \mathrm{O}$, higher values being estimated deleterious. CPAP makes of $\mathrm{H} / \mathrm{L}$ a parameter of choice as, in response to that intervention, Pdi values are difficult to ascertain.

The identification of the optimal time for weaning of ventilatory assistance may be the most significant benefit of 
real-time diaphragmatic muscle activity monitoring [1, 49, 50]. As a matter of fact, it is not rare that patients have to be re-intubated soon after a premature extubation. Diaphragmatic electrical activity assessment may thus be of particular interest in that setting. On the contrary, late extubation may lead to an increased risk of complications related to the ICU environment and also, eventually, to a greater diaphragmatic decontionning [51, 52].

Beyond its interest as an indicator for weaning, diaphragmatic muscle electrical activity measurement may also have an interest to simply evaluate diaphragmatic fatigue, as during a midazolam course or in any other clinical settings [53]. Due to the impact of ventilation fatigue in many clinical settings, the technique may be applied in fields such as surgery [54, 55], particularly in post-operative settings where the presence of a previous ventilatory pathology (COPD, emphysema, phrenic paralysis) may increase the risk, in medicine, particularly in muscular diseases (myasthenia, myopathy, dystrophy, amyotrophic lateral sclerosis), in ventilatory rehabilitation, in sports medicine, and eventually in other clinical domains where other muscles may benefit from a similar monitoring as childbirth (uterine $\mathrm{EMG}$ ), and urology monitoring (enuresis).

In patients under long-term artificial ventilation, the knowledge of $\mathrm{H} / \mathrm{L}$ [4] may thus participate of the strategy, preventing premature discontinuation or delayed decision of ventilatory assistance, as well as eventually adjustment of ventilation parameters. In anesthesia, this may lead to take in account the diaphragmatic fatigue, with a possible compensation of that specific ventilatory impairment. In all conditions, the steady integrated real-time MuRw signal processing applied to no invasive diaphragmatic monitoring through a dedicated probe may prove its efficiency, highlighting the predominant interest of the $\mathrm{H} / \mathrm{L}$ ratio parameter in the evidence based clinical decision making.

\section{ACKNOWLEDGEMENTS}

The authors are grateful to A. Boyer, Professor of Mathematics and Signal Processing, Saint Etienne, France, for his thorough review and the many helpful suggestions.

\section{CONFLICT OF INTEREST}

We declare that we have no conflict of interest.

Clinical Trials ID NCT00133939.

\section{REFERENCES}

[1] Mancebo J. Weaning from mechanical ventilation. Eur Respir J 1996; 9: 1923-31.

[2] Demoule A. Exploration de la fonction des muscles respiratoires en réanimation. Rev Mal Respir 2005; 22: 2S86-2S99.

[3] Laghi F, Jubran A, Topeli A, et al. Effect of lung volume reduction surgery on neuromechanical coupling of the diaphragm. Am J Respir Crit Care Med 1998; 157: 475-83.

[4] Roussos CS, Macklem PT. Diaphragmatic fatigue in man. J Appl Physiol 1977; 43: 189-97.

[5] Brochard L, Harf A, Lorino H, Lemaire F. Inspiratory pressure support prevents diaphragmatic fatigue during weaning from mechanical ventilation. Am J Respir Crit Care Med 1989; 139: 513-21.
[6] Gross D. Electromyogram pattern of diaphragmatic fatigue. J Appl Physiol 1979; 46: 1-7.

[7] Bellemare F, Grassino A. Evaluation of human diaphragm fatigue. J Appl Physiol 1982; 53: 1196-206.

[8] Ward ME, Eidelman D, Stubbing DG, Bellemare F, Macklem PT. Respiratory sensation and pattern of respiratory muscle activation during diaphragm fatigue. J Appl Physiol 1988; 65: 2181-9.

[9] Cohen CA, Zagelbaum G, Gross D, Roussos C, Macklem PT Clinical manifestations of inspiratory muscle fatigue. Am J Med 1982; 73: 308-16.

[10] Raoof K, Gumery PY, Quezel G, Levy P. Filtering of nonstationary electromyographic signals of respiratory muscles. ITBM 1992; 13: 77-89.

[11] Beck J, Sinderby C, Lindström L, Grassino A. Effects of lung volume on diaphragm EMG signal strength during voluntary contractions. J Appl Physiol 1998; 85: 1123-34.

[12] Zhan C, Yeung LF, Yang Z. A wavelet-based adaptive filter for removing ECG interference in EMGdi signals. J Electromyogr Kinesiol 2010; 20: 542-9.

[13] Zhang X, Wang Y, Han RPS. Wavelet transform theory and its application in EMG signal processing. IEEE Trans Signal Process 2010: 2234-8.

[14] Choujun Z, Lam Fat Y, Zhi Y. A wavelet-based adaptive filter for removing ECG interference in EMGdi signals. J Electromyogr Kinesiol 2010; 20: 542-9.

[15] Vetterli M. Multidimensional subband coding: some theory and algorithms. Signal Processing 1984; 6: 97-112.

[16] Mallat S. A theory for multi-resolution signal decomposition: the wavelet representation. IEEE Trans Pattern Anal Mach Intell 1989; 11: 674-93.

[17] Laporta D, Grassino A. Assessment of transdiaphragmatic pressure in humans. J Appl Physiol 1985; 58: 1469-76.

[18] Hamnegard CH, Wragg S, Mills G, et al. The effect of lung volume on transdiaphragmatic pressure. Eur Respir J 1995; 8: 1532-6.

[19] Lee KH, Hui KP, Chan TB, Tan WC, Lim TK. Rapid shallow breathing (frequency-tidal volume ratio) did not predict extubation outcome. Chest 1994;105: 540-3.

[20] Sieck GC, Mazar A, Belman MJ. Changes in diaphragmatic EMG spectra during hyperpneic loads. Respir Physiol 1985; 61: 137-52.

[21] Aldrich TK, Adams JM, Arora NS, Rochester DF. Power spectral analysis of the diaphragm electromyogram. J Appl Physiol 1983; 54: $1579-84$.

[22] Merckenburg JS, Mapleson W. Ventilatory assitance and respiratory muscle activity. Interaction in healthy volunteers. $\mathrm{Br}$ Anaesth 1998; 80: 422-33.

[23] Viale JP, Duperret S, Mahul P, et al. Time course evolution of ventilatory responses to inspiratory unloading in patients. Am J Respir Crit Care Med 1998; 157: 428-34.

[24] Mallat S. Characterization of Signals from Multiscale Edges. IEEE Trans Pattern Anal Mach Intell 1992;14: 891-6.

[25] Meyer Y, Roques S. Proceedings of the International Conference on Wavelets and Applications. International Conference on Wavelets and Applications; Toulouse: Editions Frontières; 1993. p. 785 .

[26] Daubechies I. The wavelet transform, time-frequency localization and signal analysis. IEEE Trans 1990; 36: 961-1005.

[27] Donoho DL, Johnstone IM. Ideal spatial adaptation by wavelet shrinkage. Biometrika 1994; 81: 425-55.

[28] Donoho DL, Johnstone IM. Minimax estimation via wavelet shrinkage. Ann Stat 1998; 26: 879-921.

[29] Coifman R, Donoho DL. Translation-Invariant De-Noising. Springer Lect Notes Stat 1995; 103: 125-50.

[30] Donoho DL. De-noising by soft-thresholding. IEEE Trans 1995; 41: 613-27

[31] Sweldens W. The lifting scheme: A custom-design construction of biorthogonal wavelets. Appl Comput Harmon Anal 1996; 3: 186200.

[32] Sweldens W. The lifting scheme: A construction of second generation wavelets. SIAM J Math Anal 1997; 29: 511-46.

[33] Daubechies I, Sweldens W. Factoring Wavelet Transforms into Lifting Steps. J Fourier Anal Appl 1998; 4: 247-69.

[34] Matheron G, Serra J, Ed. Strong filters and connectivity. New York: Academic Press 1988.

[35] Serra J. Introduction to mathematical morphology. Comput Vis Graph Imag Process 1986: 283-305. 
[36] Serra J, Vincent L. An overview of morphological filtering. Circuits Syst Signal Process 1992; 11: 47-108.

[37] Welch PD. The use of fast fourier transform for the estimation of power spectra: A method based on time averaging over short, Modified periodograms. IEEE Trans Acoust 1967; 15: 70-3.

[38] Yang KL, Tobin MJ. A prospective study of indexes predicting the outcome of trials of weaning from mechanical ventilation. N Engl J Med 1991; 324: 1445-50.

[39] Stulen FB, De Luca CJ. Muscle fatigue monitor: A noninvasive device for observing localized muscular fatigue. IEEE Trans 1982; 29: 760-8.

[40] Morel GL, Mahul P, Reche M, et al. Real-time diaphragmatic electromyogram denoising using wavelet in intensive care unit and anesthesia. Fundamental \& Clinical Pharmacology. In: Bousquet $\mathrm{P}$ Pathak A, Eds. 17th Annual Meeting of French Society of Pharmacology and Therapeutics, the 80th Annual Meeting of Society of Physiology, the 34th Pharmacology Meeting, the $14^{\text {th }}$ APNET Seminar and 11th CHU CIC Meeting; Angers, France: John Wiley \& Sons Ltd; 22-24 April 2013. p. 86.

[41] Daubechies I. Orthonormal bases of compactly supported wavelets. Commun in Pur Appl Math 1988; 41: 909-96.

[42] Sweldens W. The lifting scheme: A construction of second generation wavelets. SIAM J Math Anal 1988; 29: 511-46.

[43] Trappe WK, Liu KJR. Denoising via adaptive lifting schemes. Proc SPIE 2000; 4119: 302-12.

[44] Olkkonen H, Pesola P, Olkkonen JT. Efficient lifting wavelet transform for microprocessor and VLSI applications. IEEE Xplore $2005 ; 12: 120-2$

[45] Vassilakopoulos T, Zakynthinos S, Roussos C. Respiratory muscles and weaning failure. Eur Respir J 1996; 9: 2383-400.
[46] Lessa F, Paes C, M. Tonella R, Araújo S. Comparison of the rapid shallow breathing index (RSBI) calculated under direct and indirect form on the postoperative period of cardiac surgery. Rev Bras Fisioter 2010; 14: 503-9.

[47] Mauo-Ying B, You Shuei L, Huei-Guan S, et al. Rapid shallow breathing index and its predictive accuracy measured under five different ventilatory strategies in the same patient group. Chin J Physiol 2010; 53: 1-10.

[48] Smith-Blair N. Mechanisms of diaphragm fatigue. AACN Adv Crit Care 2002;13: 307-19.

[49] Boles J-M, Connors A, Herridge $\mathrm{M}$, et al. Weaning from mechanical ventilation. Eur Respiv J 2007; 29: 1033-56.

[50] Laghi F, Cattapan S, Jubran A, et al. Is Weaning failure caused by low-frequency fatigue of the diaphragm? Am J Respir Crit Care Med 2003;167: 120-7.

[51] Sinderby C, Beck J, Spahija J, Weinberg J, Grassin A. Voluntary activation of the human diaphragm in health and disease. J Appl Physiol 1998; 85: 2146-58.

[52] Ming Luo Y, Moxhan J, Polkey M. Diaphragm electromyography using an oesophageal catheter: current concepts. Clin Sci 2008;115 233-44.

[53] Sinderby CA, Beck JC, Lindström LH, Grassino AE. Enhancement of signal quality in esophageal recordings of diaphragm EMG. J Appl Physiol 1997; 82: 1370-7.

[54] Dureuil B, Viires N, Cantineau J, Aubier M, Desmonts J. Diaphragmatic contractility after upper abdominal surgery. J Appl Physiol 1986; 61: 1775-80.

[55] Pansard J, Mankikian B, Bertrand M, Kieffer E, Clergue F, Viars P. Effects of thoracic extradural block on diaphragmatic electrical activity and contractility after upper abdominal surgery. Anesthesiology 1993;78: 63-71.

(C) Morel et al.; Licensee Bentham Open

This is an open access article licensed under the terms of the Creative Commons Attribution Non-Commercial License (http://creativecommons.org/licenses/by-nc/3.0/) which permits unrestricted, non-commercial use, distribution and reproduction in any medium, provided the work is properly cited. 